\title{
O capital financeiro vai ao paraíso: Bitcoin, fintech 3.0 e a massificação do homem endividado
}

\section{Financial capital goes to heaven: Bitcoin, fintech 3.0 and the massification of the indebted man}

\author{
LEONARDO DE MARCHIa \\ Universidade Federal do Rio de Janeiro, Escola de Comunicação. Rio de Janeiro - RJ, Brasil \\ Universidade do Estado do Rio de Janeiro, Programa de Pós-Graduação em Comunicação. Rio de \\ Janeiro - RJ, Brasil
}

\section{RESUMO}

$\mathrm{O}$ artigo analisa a criptomoeda Bitcoin como parte de um novo setor do mercado financeiro, a fintech 3.0. Subscrevendo a tese de Maurizio Lazzarato de que a categoria do homem endividado seria a forma de governamentalidade do capitalismo contemporâneo, discute-se de que modo a Bitcoin funciona como um vetor de expansão a uma parcela da população da lógica social do endividamento. A princípio, proponho pensar a criptomoeda como mídia. A seguir, apresento uma genealogia das ideologias que animaram a criação do Bitcoin, a fim de demonstrar os valores libertários que nortearam o desenho dessa nova tecnologia. Por fim, discuto como a fintech 3.0 difunde a lógica social do homem endividado por meio de dispositivos digitais pessoais.

Palavras-chave: Bitcoin, fintech 3.0, moeda como mídia, financeirização da vida cotidiana, homem endividado

\section{ABSTRACT}

The article analyzes Bitcoin cryptocurrency as part of a new sector of the financial market, fintech 3.0. Subscribing to Maurizio Lazzarato's thesis that the category of the indebted man would be the form of governmentality of contemporary capitalism, it is discussed how Bitcoin works as a vector of expansion of the social logic of indebtedness to a portion of the population. At first, I propose to think of cryptocurrency as media. Below, I present a genealogy of the ideologies that animated the creation of Bitcoin, in order to demonstrate the libertarian values that guided the design of this new technology. Finally, I discuss how fintech 3.0 spreads the social logic of the indebted man through personal digital devices. Keywords: Bitcoin, fintech 3.0, currency as media, financialization of everyday life, indebted man

${ }^{\text {a }}$ Professor adjunto da Escola de Comunicação da Universidade Federal do Rio de Janeiro (UFRJ). Membro permanente do Programa de Pós-Graduação em Comunicação da Universidade do Estado do Rio de Janeiro (UERJ). Orcid: http://orcid.org/ 0000-0001-5654-8938. E-mail: leonardodemarchi@gmail.com 


\section{INTRODUÇÃO}

${ }^{1}$ Criptomoedas são um ativo digital de código aberto, projetado para funcionar como sistema de pagamento entre usuários de uma rede distribuída (peer-to-peer). Os registros de propriedade de moedas são armazenados em um livro-razão digital, a blockchain (cadeia de blocos de informação, numa tradução livre), que usa criptografia para proteger os registros de transações, controlar a criação de moedas adicionais

e verificar a transferência da propriedade das moedas.

${ }^{2}$ Conjunto de princípios e técnicas empregadas para cifrar uma escrita, tornando-a ininteligível para os que não tenham acesso às convenções técnicas estipuladas.

${ }^{3} \mathrm{O}$ problema do endividamento dos indivíduos (notadamente, o endividamento dos

estudantes universitários nos

Estados Unidos) assumiu protagonismo na agenda trazida pelo movimento Occupy Wall Street. Desde então, o endividamento como forma de governamentalidade passou a ser objeto de reflexão acadêmica entre intelectuais de distintas correntes teóricas (Graeber, 2011; Lazzarato, 2017).
S CRIPTOMOEDAS ${ }^{1}$, OU moedas digitais criptografadas ${ }^{2}$, ganharam
destaque como um dos ativos financeiros mais inovadores dos últimos
anos. Lançada no ano de 2008 a partir da publicação de um artigo de um desenvolvedor cuja identidade é desconhecida, mas que se apresentou sob o pseudônimo de Satoshi Nakamoto (2008), a Bitcoin parecia ser um ponto de inflexão na trajetória do mercado financeiro. Ao contrário de experiências anteriores (como a Bit-Gold ou a B-Money), seu sistema de registro, a blockchain, promete garantir a confiança necessária para o uso desse meio de troca por uma comunidade descentralizada, prescindindo de qualquer autoridade política para certificar seu valor. Além disso, as bitcoins eram oferecidas não por grandes instituições do setor financeiro, mas por desenvolvedores individuais e/ou pequenas empresas de informática (startups), revelando a emergência de novos agentes econômicos que poderiam reestruturar o mercado financeiro. Não surpreende, portanto, que a Bitcoin tenha sido saudada como o futuro da tecnologia financeira ou fintech (aglutinação da expressão em inglês financial technology).

A data de lançamento da Bitcoin é emblemática. A crise financeira causada pelo estouro da bolha do setor imobiliário (chamada crise das hipotecas ou, em inglês, subprimes) em 2007, que se iniciou nos Estados Unidos e logo se tornou global, marca um ponto de inflexão no capitalismo contemporâneo. Ao contrário das crises anteriores, que puderam ser contornadas com a criação de novas bolhas de especulação, a das hipotecas evidenciou o esgotamento da capacidade do neoliberalismo de gerar crescimento do capital (Streeck, 2018; Varoufakis, 2016). À época, emergiram revoltas populares que exigiam a regulação do capital financeiro e o fim das políticas neoliberais, as quais resultaram em crescente endividamento da população ${ }^{3}$. O movimento Occupy Wall Street foi o mais emblemático esforço nesse sentido (Harvey et al., 2012). Entre intelectuais e analistas de conjuntura política e econômica, chegou-se mesmo a declarar o fim do neoliberalismo e o retorno às políticas econômicas que têm como pressuposto a maior participação do Estado na distribuição de renda como forma de alcançar a justiça social.

O que ocorreu na sequência da intervenção estatal para sanar a crise econômica foi, contudo, justamente o contrário. Ao invés de fazer mea culpa pela especulação desenfreada, grandes bancos e agências financeiras passaram a requerer que os estados nacionais estivessem mais aptos a socorrer o setor financeiro em caso de necessidade. Porém, como os estados emprestaram dinheiro (a fundo perdido) ao setor financeiro a fim de dar liquidez à economia, a dívida pública desses países aumentou notavelmente. Na leitura do capital financeiro, isso significava que os estados não estariam mais aptos a pagar (ao próprio mercado financeiro) os juros de suas dívidas (Blyth, 2017). 
Apesar da evidente natureza paranoica desse argumento, os lobistas do mercado financeiro realizaram uma bem-sucedida pressão para que os estados não regulassem o capital financeiro e, ao contrário, acelerassem as políticas de austeridade fiscal, diminuição do investimento público em serviços públicos, desregulação do mercado de trabalho e privatização de bens comuns (água, energia, infraestrutura rodoviária etc.).

Esse movimento acarretou o aprofundamento das relações diretas entre a sociedade civil e o capital financeiro. O período neoliberal na política se caracteriza pelo deslocamento de funções sociais do Estado e pela desregulação da proteção ao trabalho. Isso traz uma série de consequências para a força de trabalho, como a diminuição geral dos salários e a transformação do desemprego e do emprego informal em fatores estruturais da economia. Sem empregos garantidos e com escassos e precários serviços públicos, a maior parte dos indivíduos passa a buscar no setor privado os bens e serviços necessários para sua subsistência. Isso aumenta de maneira inaudita o nível de endividamento pessoal, criando uma relação sistêmica de credor e devedor com o capital financeiro. Ao se valer cada vez mais de crédito privado para custear sua vida, os indivíduos passam a contrair mais e mais dívidas até o ponto em que a maior parte de seu tempo de trabalho é destinada ao pagamento de múltiplas contas, que nunca se extinguem. Surge, assim, um novo tipo de sujeito econômico, que não busca tanto maximizar seus lucros quanto pagar suas dívidas. Daí que Maurizio Lazzarato (2017) criou o conceito do homem endividado (l'homme endetté) para dar conta da subjetividade característica do capitalismo neoliberal.

Porém, após a crise financeira de 2007, como seria possível direcionar famílias e empresas a buscar mais crédito privado num cenário de depressão econômica e descrença no sistema financeiro? Uma solução possível foi a oferta de produtos financeiros que poderiam ser acessados através de dispositivos digitais pessoais, como notebooks ou telefones celulares. Não por acaso, a partir de 2009, testemunha-se o aparecimento de um crescente número de empresas digitais que oferecem acesso a produtos financeiros via internet: plataformas de crowdfunding, bancos digitais, carteiras digitais, plataformas de investimento no mercado de ações ou em títulos públicos para pessoas físicas, cashback, criptomoedas, tokenização, entre outros produtos.

Esse conjunto de plataformas digitais acabou por constituir um novo nicho do sistema financeiro, que tem sido rotulado de fintech 3.04 (Arner et al., 2015; Nicoletti, 2017). Sua peculiaridade reside menos na novidade dos produtos que oferecem (ainda que alguns sejam bastante inovadores) do que em seu público: qualquer pessoa física com disponibilidade mínima de dinheiro e acesso à internet. Assim, o mercado financeiro passaria a ter acesso não apenas
${ }^{4}$ Em sua análise do mercado financeiro após a crise das hipotecas, Arner et al. (2015) decidiram criar uma perspectiva histórica do sistema financeiro global a partir dos agentes que ofereciam produtos financeiros, ou seja, através de alguma evolução de empresas de tecnologia financeira. Numa perspectiva historicista, os autores decidiram classificar três momentos: entre $1866 \mathrm{e}$ 1987 , quando se constituiria a fintech 1.0; entre 1987 e 2008, quando há uma mudança para a fintech 2.0; e, finalmente, de 2008 até o presente momento, quando se configuraria a fintech 3.0. 
a grandes somas de dinheiro de alguns poucos grandes investidores, como também ao pouco dinheiro de milhões de pequenos investidores, os quais poderiam dar de volta a liquidez de um setor da economia esvaziado pelos temores da crise das subprimes. Sob a bandeira da democratização do mercado financeiro, o problema tanto de liquidez quanto de confiança da população em relação ao mercado financeiro havia sido amenizado não com uma forte regulação das instituições financeiras, mas com a atração de um imenso público para sua lógica especulativa. Ironicamente, pode-se afirmar que a ocupação do mercado financeiro se deu de fato, mas de maneira diametralmente inversa à intenção dos manifestantes insurgentes.

À medida que a contratação de produtos financeiros se torna mais acessível, os indivíduos se concebem mais como investidores, tendo cada um/a sua própria carteira de investimentos (coleção de investimentos financeiros que substituiriam a tradicional popança ou o fundo de garantia). Como administrador de seus próprios investimentos, cada indivíduo passa a se conceber como um gestor de seu dinheiro - ou melhor, como um empresário de si (Foucault, 2008). No entanto, é crítico entender que o empresário de si necessita assumir riscos para empreender e lucrar, ou seja, contrair dívidas. Seu objetivo como administrador é cuidar, antes de tudo, de sua dívida para não falir. Logo, todo empresário de si é, forçosamente, um sujeito endividado.

É decisivo notar que há uma dimensão ideológica que não pode ser dissociada da emergência da fintech 3.0. O empresário de si não é um mero técnico em administração de empresas, mas alguém que deve acreditar nas forças de mercado (e não na política), como a única solução para resolver problemas da vida cotidiana. Isto é, é imperativo que se internalize um conjunto de valores que tornem racional $\mathrm{o}$ ato de assumir dívidas para empreender. Em suma, trata-se de adotar um novo espírito do capitalismo, sob a égide neoliberal (Boltanski \& Chiapello, 2009).

O caso da Bitcoin é paradigmático. Seus desenvolvedores fazem parte de um movimento autodenominado cypherpunk (Assange et al., 2013), o qual defende que os indivíduos resistam à vigilância dos estados através do uso da criptografia. Seu antiestatismo deriva do anarcocapitalismo, radicalização dos princípios do neoliberalismo que pretende destituir por completo a necessidade de ter um Estado como regulador do corpo social, pregando a proteção à soberania do indivíduo através da propriedade privada e do livre mercado (Morriss, 2008; Paraná, 2020; Rothbard, 2013). Para o anarcocapitalismo, uma das maneiras de se livrar do Estado seria justamente a liberdade de entes privados emitirem suas próprias moedas, as quais seriam reguladas pela concorrência entre si (Hayek, 2011). Essa é a visão de mundo que fundamenta toda a arquitetura da Bitcoin: a blockchain permite que esse meio de troca seja garantido por um 
sistema de verificação das transações econômicas que é, a um só tempo, o meio de controle da emissão das moedas. Assim, permite-se aos usuários da comunidade virtual manter a confiança no sistema de pagamentos, prescindindo de uma autoridade política reguladora. Por isso, seus desenvolvedores sustentam que a Bitcoin é uma moeda apolítica.

Além da questão ideológica, também é decisivo notar a existência de uma dimensão comunicacional: a Bitcoin se apresenta como um sistema de inscrição de arquivamento, transmissão e processamento de informações - ou melhor, uma mídia (Kittler, 2017), cuja materialidade almeja substituir a política. Afinal, é a crença de que a arquitetura da blockchain pode certificar tecnicamente a existência de transações passadas que faz com que a comunidade de usuários de bitcoins exista e conteste qualquer tentativa de regulação da criptomoeda.

Este artigo tem como objetivo analisar a Bitcoin com parte integrante da fintech 3.0, tendo em vista o espraiamento da governamentalidade do homem endividado. Entende-se que as criptomoedas são um objeto privilegiado para se discutir a lógica de funcionamento da fintech 3.0, na medida em que se trata de uma mídia que traduz em tecnologia, de maneira singular, os valores de vertentes radicais do neoliberalismo. Trata-se, portanto, de um objeto que produz uma convergência entre filosofia política e estudos de mídia. Por um lado, proponho pensar a Bitcoin como mídia, um sistema de inscrição de informação para transformar as informações financeiras dos indivíduos - patrimônios e dívidas - em dados que podem ser negociados nas plataformas digitais. Por outro, defendo analisar como a materialidade dessa mídia incorpora os valores da filosofia política que fundamentou seu desenvolvimento, apresentando consequências políticas relevantes.

O artigo está dividido em três seções. Na primeira, analiso a criptomoeda como mídia. Em seguida, realizo uma genealogia dos valores que fundaram o desenvolvimento da Bitcoin. Finalmente, discuto o lugar da fintech 3.0 dentro do quadro mais amplo de transformações do capitalismo contemporâneo, sustentando a tese de que ela serve de vetor de massificação da lógica do homem endividado. As considerações finais são dedicadas a alinhar a fintech 3.0 aos estudos sobre economia de plataforma.

\section{UMA CONTRIBUTÇÃO ÀS TEORIAS DA MOEDA: A MOEDA COMO MÍDIA}

O capitalismo é uma economia monetária na qual a intervenção da moeda não é funcional (facilitar as trocas, a medida, a tesourização), mas política, já que ela exprime e sanciona relações de poder. (Lazzarato, 2017, p. 137) 


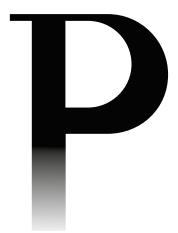

${ }^{5}$ Neste artigo, utilizo dinheiro e moeda praticamente como sinônimos, apesar de se saber que há diferenças entre tais termos. De forma geral, reserva-se a utilização da palavra dinheiro para designar a moeda moderna, dos Estados capitalistas, enquanto o termo moeda se refere a todo meio de troca utilizado ao longo da história econômica. Ver Théret (2008).

${ }^{6} \mathrm{Em}$ sua crítica à teoria liberal da moeda, Gilles Deleuze e Félix Guattari (1972/1976) rotulariam toda teoria da moeda que se baseia na ideia de troca de exchangiste, termo francês traduzido por "troquista".

A moeda é um fenômeno desafiador para qualquer ciência socioeconômica ${ }^{5}$. Ainda que seja fundamental para o funcionamento do capitalismo moderno, sua origem antecede-o. Mesmo seu uso atual apresenta um número de dimensões que excede a capacidade de explicação meramente utilitária, pois, se é verdade que toda moeda se define como meio de troca e reserva de valor, ela é também um sistema de signos, um sistema de objetos, um instrumento político e um agenciador de relações sociais.

Incrivelmente, são as teorias econômicas as que mais apresentam dificuldades para tratar do tema. Para a teoria econômica ortodoxa (liberal clássica, neoclássica e neoliberal), estabeleceu-se como pressuposto que a moeda é tão somente meio de troca, medida de valor e reserva de valor. Nessa perspectiva, a moeda teria surgido como um instrumento mais eficiente para a realização de trocas a partir da economia de escambo 6 . A moeda facilitaria a troca de bens, pois sua capacidade de representar as mercadorias superaria as limitações de tempo e de espaço inerentes ao escambo. Assim, a moeda seria uma criação funcional do mercado, um bem público resultante da busca dos agentes privados por minimizar os custos de transação inerentes ao sistema de escambo. Essa concepção acarreta como conclusão que o dinheiro tem uma dupla forma de neutralidade: lógica e política (Dodd, 1997). A neutralidade lógica sustenta que o dinheiro simplesmente medeia a troca de bens, sendo um substitutivo mais eficiente das mercadorias. A neutralidade política significa que, apesar da distribuição do dinheiro gerar desigualdades de riqueza numa sociedade, ele jamais é em si a causa da desigualdade. Tais neutralidades permitem às teorias econômicas ortodoxas eludir tanto a dimensão social do dinheiro quanto o papel do Estado em seu funcionamento (o dinheiro seria, portanto, apolítico) (Dodd, 1997; Metri, 2014).

No século XX, os economistas neoliberais retomariam o pressuposto da moeda como entidade apolítica a fim de se colocar contra as políticas econômicas de Estado. Fundamentalmente, a chamada teoria quantitativa da moeda parte da hipótese de que mudanças substanciais no nível de preços e na renda nominal são resultado de mudanças na oferta monetária nominal, ou seja, o problema da inflação estaria unicamente ligado à quantidade de moeda em circulação no mercado. Tal axioma fundamenta o argumento de Friedrich Hayek (2011) de que a melhor maneira para controlar o problema da inflação seria a emissão de moedas por entes privados, as quais competiriam entre si no mercado. A competição controlaria automaticamente a quantidade de moedas em circulação, mantendo-a num nível ideal.

Com Milton Friedman o pensamento monetarista alcança seu ápice. De forma sintética, Friedman (1984) defendia que a emissão de moeda pelo governo deveria seguir estritamente regras pré-estabelecidas e nominalmente inalteráveis, que seriam atualizadas de acordo com a taxa de crescimento da população. Se o problema da 
inflação se deve à quantidade de moeda em circulação, bastaria o controle automático da liquidez do mercado, ao invés de políticas monetárias decididas na esfera política. Friedman chegava mesmo a afirmar que se deveria substituir o banco central estadunidense, o Federal Reserve, por um computador que calculasse a quantidade de moeda necessária em determinado momento (Paraná, 2020).

A concepção liberal da moeda recebeu críticas importantes ao longo da história. A mais conhecida é a de Karl Marx (1867/1983). Ao colocar a força de trabalho do proletariado no centro de sua teoria do valor, Marx diverge da teoria econômica da moeda ao perceber nesta não um mero articulador das atividades dos produtores independentes, mas um meio através do qual o trabalho é abstraído e se torna mercadoria (commodified) para poder ser comprado e vendido no mercado de trabalho. Há, nessa definição, duas importantes implicações. A primeira é que a moeda assume a forma de uma mercadoria, ainda que de natureza especial. Note-se que também Marx percebe o dinheiro como um desenvolvimento do sistema de trocas; não como uma produção do Estado 7 .

Com efeito, a dimensão do poder soberano somente seria agregada às teorias da moeda por Georg Friedrich Knapp ao publicar, em 1905, a obra Staatliche Theorie des Geldes (A Teoria Estatal do Dinheiro), a qual funda a teoria cartista da moeda (Metri, 2014). A tese de Knapp é que a garantia do valor do dinheiro não residiria em sua paridade com os metais preciosos, mas na autoridade do Estado, o qual concede legitimidade a um meio de pagamento específico (moeda) num determinado território, sob determinado arcabouço jurídico (Metri, 2014; Weber, 1921/1999). Tal abordagem permitiu a análise da dimensão institucional da moeda (políticas monetárias, instituições financeiras etc.) como elemento endógeno ao seu valor, contrapondo-se ao pressuposto das neutralidades da moeda. Na medida em que o Estado impõe sua moeda como meio de pagamento de seus tributos (impostos), a faz circular entre a população, criando uma relação de dívida a ser paga em moeda soberana. A moeda seria, antes de tudo, um instrumento do poder do Estado.

O século XX testemunhará a profusão de teorias heterodoxas do dinheiro. Uma abordagem bastante influente é a que se pode rotular de cultural. Destacam-se, nessa perspectiva, as obras de Georg Simmel e François Simiand. Comentadores insistem em que a filosofia do dinheiro de Simmel (2004) somente pode ser entendida como uma aplicação especializada de sua teoria da modernidade, a qual sustenta o desenraizamento das relações sociais, caracterizadas pela mobilidade social, ampliação dos círculos sociais, individualização e autonomia das coisas, que passam a ser regidas por suas próprias leis (Dodd, 1997; Waizbort, 2000; Zelizer, 1994). O dinheiro aparece como o instrumento perfeito, na medida em que sua característica de abstração e anonimato confere aos indivíduos a
${ }^{7}$ É importante notar, contudo, que também Marx segue a concepção de que o dinheiro é um símbolo das contradições socioeconômicas imanentes do capitalismo, mas não sua causa direta. Esse pressuposto é visível, como sublinha Nigel Dodd (1997), em sua crítica aos proudhonianos sobre abrir mão do uso da moeda. É justamente por entender que a moeda não possui valores sociais intrínsecos que Marx vai discordar da proposta de abolição do uso do dinheiro como forma de obter igualdade social. 
liberdade de fazer alguma coisa, isto é, comprar o que puder, sem restrições sociais preestabelecidas.

O dinheiro é concebido como instrumento de troca, não guardando em si qualquer capacidade instituidora de dominação, o que reafirma a concepção da neutralidade política do dinheiro. Seu valor decorreria da percepção dos indivíduos ao avaliarem e desejarem determinados objetos, fato que constitui, como bem observa Leopoldo Waizbort (2000, p. 140), uma teoria psicologista do valor. François Simiand (2018) seguiria, por seu turno, o programa estipulado por Durkheim para a sociologia econômica, estudando a moeda como fato social (Steiner, 2018). Nesse sentido, ele desenvolve o pressuposto de que a moeda exprime o valor e equilibra as trocas porque os indivíduos que a utilizam depositam uma fé, uma crença social na manutenção de seu valor, ou seja, é no poder das coletividades que se encontra o suporte à sua existência. Nesses dois casos, ainda que de maneira diversa, a questão da confiança dos indivíduos na moeda figura como o pilar das explicações do valor do dinheiro.

A dimensão do poder imanente à moeda seria mais bem desenvolvida, mas por uma abordagem que perpassa a filosofia e a antropologia. Sua hipótese é que a razão de ser da moeda reside não na racionalidade pressuposta pela teoria liberal, mas a partir de relações sociais fundadas na concepção de dívida. Essa tese se inicia com Friedrich Nietzsche (1887/1998), em Genealogia da Moral. Como uma forma de crítica ao argumento utilitarista da troca como cimento social, o filósofo sustentou que as mnemotécnicas são desenvolvidas para inscrever a memória nos indivíduos. Posteriormente, a concepção de dívida teria se metamorfoseado nas noções de culpa, punição e compensação, logo, funcionando como força estruturante das relações sociais: estabelecem-se, assim, relações sociais hierarquizadas, baseadas na divisão fundamental entre credores e devedores.

Décadas mais tarde, Marcel Mauss (1950/2003) realizaria uma leitura que, de certa forma, ecoa a polêmica de Nietzsche em seu ensaio sobre a economia da dádiva, ao afirmar que as trocas nas sociedades primitivas seguiam a dialética do dar-receber-retribuir, elo fundador dos laços sociais nessas sociedades, afastando-se da concepção utilitarista da troca. Nesse caso, a moeda se torna não é um instrumento perfeito de troca, mas uma entidade que contém em si um poder de agenciamento social. Essa leitura heterodoxa seria retomada por autores de campos de saber tão distintos quanto a filosofia (Deleuze \& Guattari, 1972/1976; Lazzarato, 2017), a economia (Théret, 2008) e a antropologia social (Graeber, 2011). Ela será discutida, em detalhe, na terceira seção deste artigo.

No momento, é preciso reconhecer que a profusão de teorias sobre a moeda revela a existência de, pelo menos, três estados da moeda, conforme a formulação Bruno Théret (2008, pp. 12-16): 
- Estado incorporado: a confiança dos indivíduos na estabilidade do sistema monetário. A moeda constitui um meio de comunicação simbolicamente organizado - ou melhor, uma linguagem especializada que permite às pessoas se comunicarem com vistas a estabelecer relações econômicas;

- Estado institucionalizado: trata-se da moedagem e regulação ou, ainda, a dimensão institucional da moeda que forma uma comunidade de pagamento, e o poder soberano é o que determina a validade da moeda;

- Estado objetivado: instrumentos monetários, meios de pagamento e moedas correntes. Tais tecnologias são "a expressão mais pura da moeda ..., não se expressando mais ... como uma linguagem, mas por intermédio de um sistema de objetos" (p. 15).

O estado objetivado chama a atenção por ser o menos desenvolvido teoricamente. Isso porque, em certa medida, a concepção sobre a materialidade do dinheiro traz o fardo da teoria metalista da moeda ${ }^{8}$. De forma geral, essa teoria acabou se restringindo à justificação do uso do ouro (por sua divisibilidade e raridade) como lastro das moedas modernas. Com o fim do padrão ouro, em 1971, o metalismo tornou-se uma explicação obsoleta ${ }^{9}$. Infelizmente, sua decadência também arrefeceu o interesse por pensar na materialidade da moeda como um sistema de objetos.

Neste artigo, propõe-se retomar a análise da materialidade da moeda, pensando-a como mídia. Por mídia, adota-se a definição de Friedrich Kittler (2017) de toda tecnologia que realize arquivamento, processamento e transmissão de dados, constituindo um sistema de inscrição (aufschreibesysteme). Nesse sentido, cabe pensar como a estrutura tecnológica da moeda influencia a formação de seu valor e sua circulação na sociedade. Essa abordagem não prescinde dos demais estados da moeda, mas visa complexificar o debate ao propor algo mais do que uma teoria hermenêutica e/ou institucional da moeda. As moedas possuem também uma materialidade que, de diferentes maneiras, fundamenta sua aplicabilidade como meio de troca e reserva de valor: trate-se de conchas, metal precioso, papel-dinheiro ou bits, cada um desses materiais desempenha um papel na maneira pela qual as pessoas utilizam o dinheiro e, logo, na maneira pela qual o dinheiro estrutura as relações entre pessoas e mercadorias.

As criptomoedas reanimaram o interesse pela materialidade da moeda como um sistema de informação. Afinal, um dos pontos decisivos de sua novidade reside justamente na capacidade da blockchain de criar uma raridade artificial no ambiente digital e gerar um conjunto de regras (uma política monetária deflacionária, na verdade) que determina os usos e avaliações (confiança) sobre a Bitcoin.

O interesse pela materialidade da moeda não deve se deter, contudo, apenas nas qualidades físicas de cada tecnologia. Tal abordagem deve se acoplar a outro

\footnotetext{
${ }^{8}$ Título criado por Knapp a fim de criticar as teorias que sustentam que o valor da moeda é determinado pelo poder de compra da mercadoria sobre a qual está baseada. $\mathrm{O}$ problema fundamental dessa perspectiva seria não compreender que o próprio valor do ouro é determinado, em última instância, por (1) princípios culturais e (2) instituições políticas (Metri, 2014).

${ }^{9}$ Por mais estranho que pareça, as criptomoedas tentam resgatar a teoria metalista da moeda através da analogia constante que seus desenvolvedores fazem com o ouro. É notável a adoção de termos como ouro (no caso da experiência da Bit-Gold) e mineração de moedas. No paper de Satoshi Nakamoto (2008, p. 4), diz-se, literalmente, que "a adição constante de uma quantidade constante de novas moedas é análoga aos mineradores de ouro [ênfase adicionada] que gastam recursos para adicionar ouro à circulação". Alguns autores falam, inclusive, de algum metalismo digital como teoria da moeda corrente entre os desenvolvedores de criptomoedas (Maurer et al., 2013; Paraná, 2020).
} 
nível de análise, em que se busque entender a moeda como parte de um complexo de tecnologias financeiras (políticas econômicas, impostos, instituições financeiras, entre outras), formando uma axiomática, no sentido proposto por Gilles Deleuze e Félix Guattari (1972/1976), isto é, enunciados, palavras de ordem, comandos (axiomas) e correspondentes dispositivos (realização da axiomática) destinados a converter os fluxos descodificados de desejo em novas formas abstratas de valor (Guéron, 2017; Lazzarato, 2017). Em outros termos, faz-se necessário conceber a moeda como parte de uma máquina técnica que implica pessoas e coisas de formas específicas, gerando diferentes formas de subjetivação e de relações sociais. Para tanto, faz-se necessário analisar os valores que levam à adoção de certa tecnologia como moeda.

\section{CYPHERPUNKSE ANARCOCAPITALISMO: A GENEALOGIA DA MORAL DA BITCOIN E O MODUS OPERANDI DA FINTECH 3.0}

O liberalismo sempre deixou por conta dos socialistas o cuidado de fabricar utopias, e foi a essa atividade utópica ou utopizante que o socialismo deveu mui-

to de seu vigor e de seu dinamismo histórico. Pois bem, o liberalismo também necessita de utopia. (Foucault, 2008, p. 301)

A análise da Bitcoin não pode prescindir da genealogia dos valores que mobilizaram os desenvolvedores iniciais das criptomoedas. O esforço por construir um complexo sistema de informação capaz de mimetizar o processo de emissão de dinheiro a fim de competir com as moedas fiduciárias responde mais à filosofia política do que a imperativos técnicos do mercado financeiro. Afinal, a maior parte do dinheiro que circula hoje na economia global é digital, como observa Edemilson Paraná (2020). Dessa forma, a Bitcoin deve ser vista como uma mídia disjuntiva na medida em que dá concretude à uma moeda supostamente apolítica.

Um olhar atento aos desenvolvedores das criptomoedas revela que eles se colocam como membros do movimento cypherpunk. O neologismo se refere a um movimento político insurgente, de inspiração anarquista (daí a referência ao gênero musical punk), que utiliza a criptografia (cypher) como instrumento de transformação social e política. O êthos dito anarquista se refere à oposição ferrenha ao Estado, vendo neste meramente um agente de coerção à liberdade individual, entendida como capacidade de realizar ações econômicas. Como os autores do livro Cypherpunks (Assange et al., 2013) afirmam: "lembre-se de que os Estados são sistemas através dos quais fluem as forças repressoras" que, diante do novo mundo promovido pelas redes digitais em rede, "impediria [a] tão sonhada 
independência [liberdade individual] e, imiscuindo-se pelos cabos de fibra óptica, pelas estações terrestres e pelos satélites, iria ainda mais longe, interceptando em massa o fluxo de informações do nosso novo mundo" (p. 26). Para evitar que o Estado afete a liberdade individual, os cypherpunks se apresentam como vanguarda política que busca monitorar e, por conseguinte, limitar o poder dos Estados através de tecnologias digitais disjuntivas (Paraná, 2020).

O espírito antiestatal dos cypherpunks decorre de uma vertente radical do neoliberalismo, o anarcocapitalismo ou libertarianismo. O termo dá nome à filosofia política que preconiza a completa abolição do Estado, pressupondo que os agentes privados, comunitariamente associados, teriam condições de fornecer todas as condições necessárias à sobrevivência dos indivíduos através da defesa da propriedade privada e da livre concorrência (Morriss, 2008; Rothbard, 2013). De acordo com essa teoria, todos os bens e serviços públicos deveriam ser privatizados, pois a livre competição entre os agentes privados resultaria na oferta do melhor serviço possível por um preço justo - inclusive no caso da moeda. Sem o Estado, não seriam necessários impostos e, assim, as moedas poderiam ser fornecidas através de um sistema bancário livre, competindo entre si, o que garantiria o controle do volume de dinheiro disponível, logo, evitando a inflação (Hayek, 2011).

O cypherpunk acredita na inovação tecnológica como estratégia de criação de uma sociedade contra o Estado. Como bem observou Michel Foucault (2008, p. 317-319), a concepção neoliberal de capital humano permite reler a inovação tecnológica como uma alavanca do desenvolvimento social, dando novo fôlego à concepção schumpeteriana de destruição criadora ${ }^{10}$ (Schumpeter, 2010). Numa perspectiva libertária, a inovação é tida como uma linha de fuga dos empreendedores em relação ao Estado: a contínua inovação tecnológica efetuada pela sociedade civil impediria que a política interviesse para controlar o ritmo da mudança social. A criação das criptomoedas tenta realizar essa visão de mundo libertária: a criação de uma moeda tecnicamente capaz de garantir a confiança da comunidade de usuários seria o substitutivo perfeito para uma moeda-soberana atrelada aos impostos, às políticas econômicas e monetárias, enfim, ao Estado (Ulrich, 2014).

As criptomoedas começaram a ser desenvolvidas ainda nos anos 1980, quando o programador David Chaum propôs um sistema anônimo de pagamentos digitais. Na década seguinte, os desenvolvedores Nick Szabo e Wei Dai tentaram implementar duas criptomoedas que funcionariam através de sistema descentralizado de compartilhamento entre pares (peer-to-peer ou P2P), a Bit-Gold e a B-Money (Cannucciari, 2016; Paraná, 2020). A Bitcoin foi, no entanto, a primeira experiência bem-sucedida, pois era garantida por um sistema distribuído de verificação das transações, a blockchain (Nakamoto, 2008).
${ }^{10}$ Termo que se refere ao fenômeno de introdução de uma inovação (que pode ser um novo método de trabalho, produto ou tecnologia de produção, entre outras possibilidades) por um agente diferenciado dentro do mercado, o empreendedor, que provoca uma tal disjunção dos tradicionais conhecimentos, técnicas e práticas comerciais, que criaria um novo mercado. 
A blockchain é um sistema de inscrição que funciona como o livro-razão de contabilidade (onde se registram débito e crédito de uma conta), ou seja, trata-se de uma tecnologia de contabilidade digital compartilhada que registra todas as transações entre usuários da criptomoeda. As transações não são, contudo, visíveis para os usuários a priori. Necessita-se, para tanto, do trabalho dos denominados mineradores, que conferem a validade das transações registradas e, ao fazê-lo, recebem como uma forma de prêmio (proof of work) certa quantidade de novas moedas. Note-se que o mecanismo da blockchain foi desenvolvido, portanto, para por em marcha uma verdadeira política monetária automática. Seu modus operandi evita o problema do gasto duplo, ou seja, a utilização da mesma moeda mais de uma vez em diferentes transações (fraude no sistema de trocas). $\mathrm{O}$ arquivo das transações garante que uma unidade de bitcoin usada numa transação seja retirada do mercado até que seu receptor a utilize em uma nova negociação. Cria-se, assim, uma raridade artificial para a criptomoeda. Concomitantemente, o algoritmo da Bitcoin controla expressamente a emissão das moedas ao longo do tempo. Na medida em que a comunidade de usuários cresce, a mineração se torna mais difícil. Assim, a emissão de moedas é ralentada e a liquidez do mercado é proporcional à população da comunidade. Aqui se revela a influência da teoria quantitativa da moeda sobre as criptomoedas: como uma verdadeira realização do sonho friedmaniano, o algoritmo-base da Bitcoin está programado para que, no ano de 2140 , haja invariavelmente uma oferta de 21 milhões de bitcoins no mercado digital (Paraná, 2020; Ulrich, 2014).

A data de publicação do artigo que dá início à Bitcoin, o ano de 2008, é emblemática porque se inscreve num momento de crise do mercado financeiro e de questionamento da capacidade dos estados de evitarem crises econômicas. A crise financeira das hipotecas teve, pelo menos, duas importantes consequências imediatas para o mercado financeiro. Desde logo, houve uma grande quantidade de demissões de agencias de investimento e grandes bancos, despejando no mercado de trabalho uma mão de obra altamente qualificada. Ao mesmo tempo, a crise econômica marcou um momento de crítica popular ao mercado financeiro e seus produtos, notadamente os derivativos. Movimentos como Ocuppy Wall Street, que se repetiram ao redor do mundo sob o nome de Indignados, revelaram extrema insatisfação popular com as políticas neoliberais e o capital financeiro (Harvey et al., 2012). Chegou-se mesmo a considerar aquele momento como o fim do neoliberalismo e a retomada de políticas econômicas mais intervencionistas ou de matriz neokeynesiana ou socialista. Não obstante, ao invés de realizarem esforços para produzir alguma eutanásia do rentista, retomando a famosa expressão de Keynes, as medidas tomadas visaram, paradoxalmente, a aceleração das receitas neoliberais. 
Para aumentar a liquidez nos mercados financeiros, certos governos decidiram apostar na facilitação do acesso da população ao crédito concedido por entes privados. O melhor exemplo foi o esforço do governo estadunidense para redesenhar seu sistema financeiro. Enquanto medidas foram tomadas para controlar a emissão de derivativos por grandes bancos e financeiras, buscou-se desenvolver meios de oferecer acesso a produtos financeiros a baixo custo e da forma a mais simples possível.

Em 2012, o governo lançou o plano denominado Jumpstart Our Business Startups Act (numa tradução aproximada, algo como Lei Acelerador de Criação de Empresas). Seu principal objetivo era incentivar startups que oferecessem serviços financeiros, com o mínimo de burocracia para um público amplo ou, precisamente, "aumentar a criação de emprego e o crescimento econômico americanos, melhorando o acesso ao mercado público de capitais para empresas emergentes em crescimento"11 (Jumpstart Our Business Startups Act citado por Arner et al., 2015, p. 17). Na verdade, o governo queria atingir dois objetivos com um só golpe. Por um lado, esperava-se que tais empresas gerassem ocupações para os diversos profissionais especializados em finanças que se encontravam desempregados. Por outro, desejava-se fornecer crédito para uma grande quantidade de pessoas cujas condições de vida encontravam-se precárias não através de programas sociais do Estado, mas do próprio mercado financeiro, que, então, se encontrava com baixa liquidez.

$\mathrm{Na}$ prática, buscou-se alavancar o mercado financeiro através do pouco dinheiro de milhares de novos investidores. Não foi por coincidência que, desde então, testemunha-se o crescimento de plataformas digitais que lidam com produtos financeiros de diferentes naturezas: plataformas de crowdfunding, bancos digitais, máquinas de pagamento em crédito e débito para pequenos empreendedores, plataformas de investimento em ações (day trade), criptomoedas, tokenização, entre outros serviços oferecidos a pessoas físicas. Em seu conjunto, tais empresas caracterizariam um novo setor de mercado financeiro, a fintech 3.0 (Arner et al., 2015; Nicoletti, 2017).

Para compreender a especificidade da fintech 3.0, busquei acessar os usuários de bitcoins através de entrevistas individuais compreensivas ${ }^{12}$. Com efeito, essa técnica de pesquisa me ajudou a entender o papel que as interfaces dos aplicativos das empresas financeiras desempenham para conectar de maneira direta os indivíduos ao complexo mercado financeiro.

Para comprar bitcoins, por exemplo, basta abrir uma conta numa exchange (plataforma digital de compra e venda da criptomoeda) através de uma página na internet ou um aplicativo de smartphone. A partir do preenchimento de um breve cadastro, a blockchain produz uma identificação digital da carteira da/o
${ }^{11}$ No original: “To increase American job creation and economic growth by improving access to the public capital markets for emerging growth companies". Esta e demais traduções, do autor.

${ }^{12}$ Entre 11 de junho de 2020 e 10 de abril de 2021, foram conduzidas quinze entrevistas individuais, de natureza compreensiva, com usuários da Bitcoin. O objetivo das entrevistas foi conhecer as práticas de utilização da criptomoeda e impressões dos usuários sobre sua interação com o mercado financeiro. Conforme postula Jean-Claude Kaufmann (2013, p. 47), a entrevista compreensiva é um método de pesquisa qualitativo e tem por objetivo compreender a racionalidade dos atores sociais, como organizam e justificam suas ações; não há busca de alguma verdade dos atos por trás das falas que proferem. Apesar de se desejar ter realizado um acompanhamento mais próximo das práticas dos usuários de Bitcoin, o período de pesquisa coincidiu com a pandemia da Covid-19, o que tornou impraticável técnica e eticamente, para se dizer o mínimo, um contato mais próximo com os entrevistados. As entrevistas seguiram um roteiro semiestruturado, sendo realizadas através de e-mail ou aplicativos de reunião remota (Zoom, Google Meet ou WhatsApp). A fim de proteger a identidade dos entrevistados, decidiu-se utilizar nomes fictícios nas citações. 
${ }^{13} \mathrm{Nas}$ entrevistas realizadas para esta pesquisa, $60 \%$ das/os entrevistados/as não possuía experiência em investimentos financeiros (salvo a compra de moeda estrangeira para viagens pontuais ao exterior). Um percentual de $30 \%$ tinha como única experiência a compra de títulos públicos do Estado brasileiro através do sistema Tesouro Direito. O restante tinha certa experiência em mercado financeiro, sobretudo em bolsa de valores (ações). usuária/o, que pode realizar a compra da criptomoeda pela transferência de moeda nacional diretamente de sua conta num banco para sua carteira digital.

Em entrevista para esta pesquisa, Laura aparece como uma típica investidora da fintech 3.0: uma mulher por volta de 40 anos, de classe média, residente num grande centro urbano do Brasil, com pouca experiência no mercado financeiro ${ }^{13}$. Sua vontade de investir em bitcoins se deveu ao conhecimento que ela teve por meio de um amigo que especulava com esse ativo. Ela descreveu sua interação com a plataforma digital através da qual investiu em Bitcoin:

Eu utilizei tanto o aplicativo no celular quanto o site das exchanges ... mas preferia os sites porque eles apresentam informações mais completas. Os gráficos que eles mostram podem apresentar complexidades diferentes, desde para iniciantes até para profissionais, tem várias configurações. (Entrevista concedida em 11 jun. 2020)

O acompanhamento das transações é feito pelo próprio investidor através do site e/ou aplicativo da exchange. As transações são automáticas, feitas pelos algoritmos das plataformas, que assumem o papel dos agentes de mercado financeiro (brokers), como descreve a mesma investidora:

As cotações e transações são automáticas. Lá no site tem pessoas querendo comprar e pessoas querendo vender e essas pessoas realizam as transações entre elas, por meio de ordens de compra ou de venda. A plataforma ganha com as taxas que cobra por cada transação, mas os usuários não têm contato com os mineradores, por exemplo. (Entrevista concedida em 11 jun. 2020)

Ao comentar sobre como seu amigo negociava bitcoins, Laura sublinhou:

O meu amigo era investidor autônomo, ele investia o próprio dinheiro em várias plataformas diferentes e passava os dias (as noites e às vezes as madrugadas) comprando e vendendo essas moedas. É tipo a bolsa de valores, sim. Hoje a variação do Bitcoin está fechando em -5,34\%, é muita coisa para 24 horas. Se fizer os movimentos certos dá para ter bastante lucro. (Entrevista concedida em 11 jun. 2020)

A descrição é interessante, na medida em que aponta para um agenciamento homem-máquina típico da fintech 2.0, conforme foi descrito no trabalho de Karin Knorr-Cetina e Urs Bruegger (2000) ao falarem dos market makers (agentes de venda de derivativos) do Swiss Bank. Conforme descreveram, tais agentes trabalhavam acoplados a cinco telas de televisão para acompanhar as informações do mercado: 
Mais notáveis, no entanto, são as até cinco telas de computador que confrontam cada operador, exibindo o mercado e servindo para realizar negociações. Quando os comerciantes chegam de manhã, eles se prendem aos seus assentos, falando figurativamente, exibem suas telas e, a partir de então, seus olhos ficam colados a essa tela, sua consideração visual capturada por ela, mesmo quando conversam ou gritam entre si, e seu corpo e o mundo da tela se fundem no que parece ser uma imersão total na ação em que estão participando. As telas, por sua vez, capturam o mercado, que existe apenas na tela, onde chega o mais perto possível do sentido etnometodológico de um fenômeno produzido localmente ${ }^{14}$. (p. 146)

Essa citação torna possível entender uma importante especificidade da fintech 3.0: ao se converter em investidor através de seus dispositivos pessoais de comunicação, cada indivíduo se assemelha aos profissionais do mercado financeiro, os quais se conectam com tecnologias da informação o tempo todo para não perder oportunidades de lucro. Em outros termos, a fintech 3.0 reproduz, na escala do indivíduo, as práticas e os valores do mercado financeiro global. Assim, incorpora-se ao cotidiano dos indivíduos um modo de viver e, no limite, uma ética fundamental à legitimação do capital financeiro através das tecnologias da informação.

É verdade que a implementação da Bitcoin acabaria expondo as aporias da ideologia que propiciou o desenvolvimento das criptomoedas (Paraná, 2020). O uso de bitcoins para atividades ilegais, como a compra de drogas e armamentos através de redes alternativas de computadores, e fraudes, sendo a falência da plataforma MT Gox o caso mais emblemático, colocou em xeque o objetivo de utilizar tal tecnologia como uma efetiva moeda concorrente às moedas soberanas $^{15}$. Não obstante, a proliferação de novas criptomoedas e a extrema valorização da Bitcoin em anos recentes revela tanto a força de mobilização social do anarcocapitalismo quanto a capacidade de penetração da fintech 3.0 em certas camadas da população.

\section{A FINTECH 3.0 E A MASSIFICAÇÃO DO HOMEM ENDIVIDADO}

Isso mostra, além do mais, que não te esqueces das tuas dívidas, fazendo com que pareças um homem tão cuidadoso quanto honesto, e isso aumenta teu crédito. (Franklin, citado por Weber, 1920/2004, p. 44)

Em resumo, o dinheiro, a circulação do dinheiro é o meio de tornar a dívida infinita. (Deleuze \& Guattari, 1972/1976, p. 250)
${ }^{14}$ No original: "Most conspicuous, however, are the up to five computer screens confronting each trader, displaying the market and serving to conduct trading. When traders arrive in the morning they strap themselves to their seats, figuratively speaking, they bring up their screens, and from then on their eyes will be glued to that screen, their visual regard captured by it even when they talk or shout to each other, and their body and the screen world melting together in what appears to be a total immersion in the action in which they are taking part. The screens in turn capture the market, which exists only on screen, where it comes as close as one can get to the ethnomethodological sense of a locally produced phenomenon".

${ }^{15}$ Para alguns economistas, as criptomoedas sequer devem ser consideradas moedas propriamente, na medida em que elas não possuem a capacidade de liquidar contratos numa jurisdição nacional (Gala, 2018; Paraná, 2020). Tratar-se-ia, portanto, de um ativo para fins de mera especulação financeira. 
${ }^{16}$ Como lembra Lazzarato (2017), "a economia política que se 'apropriou' da categoria de 'valor' ao fazê-la derivar da troca, .... Para criticar os valores econômicos e morais, é preciso que 'o próprio valor desses valores deva ser colocado em questão' [citação de Nietzsche]. Não se poderia estar mais distante da teoria de Adam Smith" (p. 81).

${ }^{17}$ Esse entendimento é o que faz Deleuze e Guattari (1972/1976) afirmarem que "a sociedade não é troquista, o socius é inscritor: trocar, não, mas marcar os corpos que são da terra" (p. 234).

${ }^{18}$ Como os tradutores $\mathrm{e}$ comentadores da obra de Nietzsche sublinham, é fundamental observar o jogo de palavras que o autor utiliza, pois, em alemão, schuld significa tanto culpa quanto divida, assim

como seu adjetivo derivado, schuldig, significa tanto culpado quanto endividado.
A ampliação da oferta dos produtos do mercado financeiro através de plataformas digitais apresenta consequências além do acesso generalizado ao crédito e o conseguinte aumento da liquidez da economia. Ela também se apresenta como um dispositivo de subjetivação (ética) e criação de relações sociais (governamentalidade), pois, como sustentam certas vertentes da teoria social, o capitalismo não se restringe a operações de trocas comerciais utilitárias, mas produz modos de subjetivação e circuitos de afetos próprios que promovem o funcionamento e reprodução do sistema. Herdeiro dessa linha de pensamento, Maurizio Lazzarato (2017) avança a hipótese de que o modelo de subjetividade do capitalismo financeiro contemporâneo ou, ainda, o novo espírito do capitalismo é o homem endividado.

Sua tese retoma a discussão de Deleuze e Guattari (1972/1976) sobre a dívida como força estruturante das relações sociais. Essa hipótese é fundamentada, por seu turno, na releitura que esses autores fizeram de Nietzsche. Em Genealogia da Moral, Nietzsche (1887/1998) se colocou contra a teoria econômica liberal ao buscar na origem da responsabilidade - do que é bem ou mal, da culpa a fundação da ideia de valor, que só posteriormente seria apropriada pelo discurso econômico ${ }^{16}$. Contrário à pressuposição liberal de que o homem seria naturalmente propenso à troca e ao comércio, o filósofo apontaria a dívida e a moralidade que lhe é inerente como os pilares da subjetivação e, por extensão, das relações sociais. Notadamente em sua segunda dissertação, ele sustentou que nas supostas sociedades originais - o que chamava de pré-história do homem -, o marco da evolução que separou o homem dos outros animais foi o desenvolvimento de técnicas de inscrição da memória nos indivíduos (mnemotécnicas), criando, assim, uma relação de responsabilidade coletiva.

Isso tornou o homem "um animal que pode fazer promessas" (Nietzsche, 1887/1998, p. 47), ou seja, um ser cuja promessa é a da retribuição pela dívida que representa sua existência para com os ancestrais de tempos imemoriais e seus representantes entre os existentes (espíritos, plantas, animais totêmicos). Para tanto, porém, foi preciso criar uma mnemotécnica para a inscrição da memória da dívida sobre o próprio corpo do indivíduo. Em sociedades orais, a memória da dívida é inscrita sobre o corpo através da dor - dilacerações, tatuagens, cicatrizes, um sistema de crueldades que torna a memória indelével -, o que gera na psique uma relação de reverência, ou melhor, relações hierárquicas entre credores e devedores ${ }^{17}$ - a equivalência entre dano e dor que se transmuta em submissão do devedor ao credor.

Nietzsche (1887/1998) ainda acrescentaria que, na sociedade europeia, o cristianismo levara tal lógica a um segundo estágio: com a invenção da escrita, pôde-se proceder à internalização da memória da dívida existencial, através da culpa (schuld, em alemão) pela dívida (schuld, em alemão) original ${ }^{18}$. 
Max Weber (1920/2004) aprofundaria essa ideia, conectando a ética protestante ao que chamou de espírito do capitalismo, ou seja, a necessidade da internalização de uma disposição normativa historicamente específica para justificar a acumulação sistemática de dinheiro através do trabalho racionalizado.

Em O Anti-Édipo, Gilles Deleuze e Félix Guattari (1972/1976, p. 241-244) retomariam a tese nietzschiana, lembrando que, se nas sociedades primitivas a dívida determinava alianças laterais entre diferentes linhagens ou clãs, ela se extinguia a cada matrimônio ou contradom, dando início a uma nova dívida. A dívida seria, assim, finita. Com o advento do Estado, porém, dá-se o deslocamento da dívida. Esta seria controlada por uma máquina despótica que imporia aos súditos uma dívida em relação ao déspota, o qual se apresentava como um ente transcendente àquela sociedade. Dessa forma, a dívida se transmutou em infinita e transcendente, a ser paga não mais à terra, mas a um ser transcendente por meio de uma moeda soberana que flui através dos impostos ${ }^{19}$.

Com o advento do capitalismo e seu desencantamento do mundo, a dívida continuou a ser infinita, uma vez que as vidas dos cidadãos parecem depender da capacidade do Estado de prover segurança contra algum suposto estado de guerra de todos contra todos. Não obstante, ela se torna imanente, pois o Estado já não representa uma entidade transcendente, mas uma máquina de gestão da vida da população para que ela seja produtiva para o capital. Aqui, entra em cena o que se pode chamar de uma teoria da moeda de Deleuze e Guattari (Guéron, 2017). Para os dois autores, no capitalismo, a moeda apresentaria uma dupla dimensão: num nível fundamental, ela é meio de troca que compõe o poder de compra dos trabalhadores, mas essa dimensão estaria subordinada a outra, na qual a moeda é moeda-capital que determina o valor efetivo de compra da moeda-troca e tem como fim a produção de mais moeda-capital (Deleuze \& Guattari, 1972/1976, pp. 301-304).

Acoplada aos impostos e às políticas monetárias, é a moeda-capital que instala a dívida infinita para com o capital como força estruturante das relações sociais. Daí que se pode afirmar que "a moeda de crédito exprime 'o poder do capital, enquanto a moeda mercantil exprime a 'impotência' do assalariado" (Lazzarato, 2017, p. 117). Ao invés de livrar os indivíduos da dívida nominal, a moeda-capital impõe ao socius a dívida infinita com o capital, mediada pelo Estado de bem-estar social: pois todo o dinheiro gerado com o trabalho reflui para o pagamento de impostos e o consumo de bens e serviços, portanto, a reprodução do próprio sistema.

Deleuze e Guattari (1972/1976) se ocuparam da lógica do Estado de bem-estar social, o qual tinha nas políticas sociais certa estratégia de redistribuição de renda, logo, exercendo a mediação entre os interesses do capital e do trabalho. Maurizio Lazzarato (2017) retomaria essa tese para pensar o capitalismo neoliberal. Ele defende que o neoliberalismo representa outro momento do capitalismo,
${ }^{19}$ Daí que a análise do dinheiro não possa ser isolada dos impostos, como fazem as teorias liberais. Como observa Lazzarato (2017, p. 32): "se 'a moeda é sempre distribuída por um aparelho de poder', sua circulação e sua rotação, bem como a equivalência bem/serviços/dinheiro, se estabelecem mediante o imposto, que faz do dinheiro um equivalente geral. ... A moeda é indissociável não do comércio e do trabalho, mas do imposto - instrumento de poder que é estrangeiro e independente do mercado". 
no qual se deu a ascendência do capital financeiro sobre outras formas de capital (industrial e comercial), fazendo com que a função estabilizadora do Estado se tornasse obsoleta e, com isso, a dívida da sociedade civil passasse diretamente ao capital financeiro. Afinal, o pilar das políticas econômicas neoliberais reside na privatização de bens e serviços públicos e na concomitante facilitação do acesso privado ao crédito, que é dívida, como alavanca da vida social, no lugar das anteriores políticas sociais que distribuíam a renda.

Como diversos críticos têm argumentado, se há algo de novo no dito neoliberalismo é que ele se caracteriza por abandonar a crença típica do liberalismo clássico de que bastaria restringir a ação do Estado na vida social para que o Homo oeconomicus, o sujeito racional com relação a fins, naturalmente predisposto ao comércio, se materializasse. Para os neoliberais, a disposição para empreender deve ser institucionalmente construída, a partir do estabelecimento de políticas que incitem os indivíduos a assumir riscos para obter maiores possibilidades de lucro ou, em outras palavras, torna-se necessário que cada indivíduo se conceba como uma empresa pela qual é responsável (Boltanski \& Chiapello, 2009; Dardot \& Laval, 2016; Foucault, 2008). Daí que se operam transformações institucionais a fim de fazer os indivíduos desconfiarem da capacidade da política de resolver seus problemas cotidianos e buscarem no mercado um substitutivo para sua sobrevivência.

Ao realizar esse movimento, os indivíduos passam a assumir a responsabilidade -ou melhor, a culpa (schuld) - pela gestão de suas finanças. Concebendo-se como uma empresa que precisa inovar para triunfar num mercado altamente competitivo, cada indivíduo deve buscar crédito para empreender (valorizar seu capital humano) e, para tanto, assume certo endividamento (schuldig), que contém o risco de fracasso. Deve-se lembrar que o endividamento sempre acarreta a interiorização de uma moral, pois, como lembra nietzscheanamente Lazzarato (2017), "a relação credor/devedor exprime a atividade de adestramento e de formação da subjetividade, antes de ter uma significação 'econômica' no sentido moderno do termo" (p. 82).

A prova da subjetivação da moral que se estabelece entre credor e devedor se encontra no insistente axioma de defesa da austeridade fiscal tanto para o Estado quanto para as famílias. Como insiste Mark Blyth (2017), o argumento da austeridade fiscal é antes uma filosofia moral do que uma teoria econômica, pois as contas do Estado não são equivalentes às das famílias - estas não podem emitir moeda, definir taxas de juros, cobrar impostos, lançar títulos de suas dívidas para se financiar etc. No entanto, tal argumento serve para constranger o Estado a se retirar de suas funções sociais ao mesmo tempo que obriga os indivíduos a adotarem uma política orçamentária para cuidar de suas contas privadas.

O crescente endividamento de indivíduos faz com que se torne necessário incorporar à economia doméstica técnicas de administração de riscos. Sendo 
assim, não surpreende que o mercado financeiro seja apresentado como um modelo ideal para a gestão da vida social. Afinal, sua razão de ser é a gestão de riscos. O resultado é a financeirização da vida cotidiana (Martin, 2002), cujo paradigma é o derivativo ${ }^{20}$.

Os derivativos contemporâneos são produtos financeiros criados a partir de fórmulas matemáticas baseadas em teorias probabilísticas. Isso lhes transforma em um dispositivo que permite que o risco associado a cada contrato seja desacoplado dos ativos subjacentes ou eventos futuros que embasam os documentos originais (Bryan \& Rafferty, 2014; Lépinay, 2011). Através de Inteligência Artificial (IA), reúnem-se vários contratos de seguros, que são divididos em inúmeros fragmentos, tecnicamente rotulados como atributos, para, em seguida, ser condensados em produtos financeiros sob variados títulos (CDO, Swaps, Opções, entre outros) que, contudo, realizam a mesma função: repassar as dívidas de outrem, prometendo baixo risco aos credores. Como cada produto financeiro não depende do cumprimento ou não de um determinado seguro, gera-se uma ideia de que o derivativo é um produto de risco que não contém risco para os investidores, uma vez que se tornou tecnicamente possível transferir dívidas para terceiros ad infinitum (Varoufakis, 2016). Para os credores, a dívida nunca é nominal, pois não lhe pertence.

Certos autores sustentam que a técnica dos derivativos ensejou novos métodos de gestão do trabalho, algo que se convencionou chamar de lógica social de derivativo (Arnoldi, 2004; Brayan \& Rafferty, 2014; Martin, 2013). À medida que as políticas neoliberais retiram direitos sociais, os contratos de trabalho, habitação, educação ou saúde, entre outros serviços tradicionais, têm seguido o modelo de decompor cada acordo em atributos, os quais podem ser cobrados separadamente. Mesmo a força de trabalho já não é mais vendida inteiramente: a categoria de trabalho intermitente permite que o trabalhador-empresa forneça um serviço durante um tempo determinado para outra pessoa jurídica. Tal fractalização do tempo de trabalho (Berardi, 2018) implica toda uma nova subjetividade por parte do trabalhador, que passa a se conceber como um ativo, e novas formas de relações sociais - isolamento social.

A fintech 3.0 promove o aprofundamento da financeirização da vida cotidiana ao oferecer serviços financeiros para indivíduos de maneira inédita: através de seu próprio computador pessoal ou smartphone, qualquer pessoa pode abrir uma conta digital, realizar a compra e venda de produtos e serviços financeiros, obter um cartão de crédito ou negociar bitcoins. Não se faz necessário ir a um banco ou a uma casa de câmbio para fazer negócios, escapando-se, assim, da tradicional burocracia do grande sistema financeiro e de cobrança de impostos pelo governo. Porém, ao contrário dos produtos da fintech 2.0, que lidavam com grandes investidores, negociado dívidas de outrem entre si, a fintech 3.0 se
${ }^{20}$ Derivativo é uma modalidade de seguro contra riscos, sendo um contrato no qual se estabelecem pagamentos futuros, cujos valores são calculados com base assumida num ativo subjacente, como o preço de uma ação, commodity, instrumento financeiro ou ocorrência de evento. Seu objetivo é proteger os agentes econômicos contra flutuações de preços ao longo do tempo. Ver Arnoldi (2004), Bryan e Rafferty (2014), Lépinay (2011), Martin (2013). 
destina a indivíduos identificáveis. Este é outro ponto decisivo: tais empresas de informação desenvolvem dispositivos que associam a dívida contraída às pessoas físicas através de seus dispositivos digitais.

É nesse ponto que a materialidade da mídia digital se prova decisiva. A capacidade de memória e seus sistemas de segurança servem para inscrever digitalmente nos indivíduos suas dívidas. Ao comentar sobre o cartão de crédito, Lazzarato (2017) observa que:

A relação credor/devedor está inscrita no chip do seu cartão de crédito e, em vez de desaparecer, ele a carrega no bolso, como se ele carregasse consigo sua relação com a finança. Cada compra é um ato financeiro, que mobiliza o crédito e a dívida. O cartão de crédito abre as portas da sociedade de consumo e, solicitando, encorajando e facilitando a compra, ele envolve o consumidor/devedor no círculo vicioso da excitação/frustração. A condição e a consequência da repetição infinita do ato de consumo é a dívida infinita. (p. 68)

Agora, o celular ou o notebook se tornaram a agência bancária dos bancos digitais (Nubank, C6 Bank), conectando-se às carteiras digitais (PicPay) e aos aplicativos de educação financeira (Mobills, Wallet), os quais contêm os dados financeiros de cada usuário. As plataformas digitais se conectam uma à outra, compartilhando os dados financeiros de cada usuário. Nesse cenário, as criptomoedas prometem um aprofundamento da vigilância sobre a dívida individual via blockchain: esse sistema de inscrição pode gerar um controle perfeito sobre cada transação e a dívida de cada usuário.

${ }^{21}$ Em meados de 2021, os bancos centrais do Reino Unido e do Brasil apresentaram diretrizes para implementar versões digitais de suas moedas soberanas.

\section{CONSIDERAÇÕES FINAIS}

Não se trata de prever, por fim, o futuro da Bitcoin. Ela tanto pode se consolidar como a principal criptomoeda do mercado quanto ser superada por tecnologias concorrentes, como a Libra, do Facebook Inc., ou, no limite, pode mesmo desaparecer no futuro próximo. Tal criptomoeda importa, fundamentalmente, pois (1) provou que as criptomoedas são tecnicamente possíveis de operar de acordo com valores políticos estritos e (2) desenvolveu uma tecnologia (blockchain) capaz de permitir a criação de outros ativos financeiros, na medida em que gera uma raridade artificial no ambiente digital. Não é por acaso que, a despeito das polêmicas envolvendo a Bitcoin, até mesmo bancos centrais de alguns países tenham apresentado diretrizes para implementar suas próprias criptomoedas ${ }^{21}$ e a blockchain esteja sendo utilizada para fins variados, como a produção de contratos inteligentes (smart contracts) ou tokenização 
(a substituição dos dados reais por outros equivalentes, com mesmo formato e protegidos por uma chave de criptografia).

A capacidade das criptomoedas de operar como um sistema de arquivamento, processamento e distribuição de dados financeiros pessoais revela-se como decisiva para o capitalismo contemporâneo. Deve-se lembrar que a economia digital é uma economia de exploração dados pessoais (Srnicek, 2018). Atualmente, os fluxos de débito e crédito podem ser armazenados em plataformas digitais, as quais vigiam o nível de endividamento individual e, dependendo do caso, podem oferecer ou serviços de uma empresa de crédito, em caso de dívidas agudas, ou de investimento, caso haja liquidez na conta do usuário. Além disso, tais dados podem ser negociados no mercado financeiro, em forma de derivativos. O que se negocia entre as plataformas digitais são, mais do que somas de dinheiro, as informações de movimentação financeira individuais. Ao invés de esperar que a demanda busque os serviços financeiros, os algoritmos podem oferecer aos usuários das plataformas diversos produtos, o que lhes enreda num ecossistema de produtos financeiros. Por isso é possível afirmar que a fintech 3.0 se torna um sistema de inscrição da dívida individualizada. Longe de ser disruptivo - para utilizar um termo nativo - em relação às práticas do mercado financeiro, a fintech 3.0 promete levá-lo ao paraíso, estendendo sua lógica a cada indivíduo de toda uma população. $\mathbf{M}$

\section{REFERÊNCIAS}

Arner, D. W., Barberis, J. N., \& Buckley, R. P. (2015). The evolution of fintech: A new post-crisis paradigm? UNSW Law Research Paper, 216(62), 1-15. https://dx.doi.org/10.2139/ssrn.2676553

Arnoldi, J. (2004). Derivatives: Virtual values and real risks. Theory, Culture \& Society, 21(6), 23-42. https://doi.org/10.1177/0263276404047414

Assange, J., Appelbaum, J., Müller-Maghun, A., \& Zimmermann, J. (2013). Cypherpunks: Liberdade e o futuro da internet. Boitempo.

Berardi, F. (2019). Depois do futuro. Ubu.

Blyth, M. (2017). Austeridade: A história de uma ideia perigosa. Autonomia Literária.

Boltanski, L., \& Chiapello, Ė. (2009). O novo espírito do capitalismo. Martins Fontes. Bryan, D., \& Rafferty, M. (2014). Financial derivatives as social policy beyond crisis. Sociology, 48(5), 887-903. https://doi.org/10.1177/0038038514539061 Cannucciari, C. (Diretor). (2016). Banking on Bitcoin [Filme]. Gravitas Venture. Dardot, P., \& Laval, C. (2016). A nova razão do mundo: Ensaio sobre a sociedade neoliberal. Boitempo. 
Deleuze, G., \& Guattari, F. (1976). O Anti-Édipo: Capitalismo e esquizofrenia. Imago. (Trabalho original publicado em 1972)

Dodd, N. (1997). A sociologia do dinheiro. Editora FGV.

Foucault, M. (2008). Nascimento da biopolítica. Martins Fontes.

Friedman, M. (1984). Capitalismo e liberdade. Abril Cultural.

Gala, P. (2018, 1 de abril). Bitcoin não é moeda de verdade, cuidado! Money Times. https://bit.ly/3uvX2W7

Graeber, D. (2011). Debt: The first 5.000 years. Melville House.

Guéron, R. (2017). A axiomática capitalista segundo Deleuze e Guattari: De Marx a Nietzsche, de Nietzsche a Marx. Aurora, 29(46), 257-282. http://dx.doi.org/10.7213/1980-5934.29.046.DS14

Harvey, D., Teles, E., Sader, E., Alves, G., Carneiro, H. S., Wallerstein, I., Peschanski, J. A., Davis, M., Žižek, S., Ali, T., \& Safatle, V. (2012). Occupy: Movimentos de protesto que tomaram a rua. Boitempo; Carta Maior.

Hayek, F. (2011). Desestatização do dinheiro: Uma análise da teoria e prática das moedas simultâneas (2a ed.). Instituto Von Mises Brasil.

Kaufmann, J.-C. (2013). A entrevista compreensiva: Um guia para pesquisa de campo. Vozes; Edufal.

Kittler, F. (2017). A verdade do mundo técnico: Ensaios sobre a genealogia da atualidade. Contraponto.

Knorr-Cetina, K., \& Bruegger, U. (2000). The markets as an object of attachment: Exploring postsocial relations in financial markets. Canadian Journal of Sociology, 25(2), 141-168. https://doi.org/10.2307/3341821

Lazzarato, M. (2017). O governo do homem endividado. N-1 Edições.

Lépinay, V. A. (2011). Codes of finance: Engineering derivatives in a global bank. Princeton University Press.

Martin, R. (2002). Financialization of the daily life. Temple University Press.

Martin, R. (2013). After economy? Social logics of derivative. Social Text, 31(1), 83-106. https://doi.org/10.1215/01642472-1958908

Marx, K. (1983). O capital: Crítica da economia política. Abril Cultural. (Trabalho original publicado em 1867)

Maurer, B., Nelms, T. C., \& Swartz, L. (2013). When perhaps the real problem is money itself! The practical materiality of Bitcoin. Social Semiotics, 23(2), 261-277. https://doi.org/10.1080/10350330.2013.777594

Mauss, M. (2003). Sociologia e antropologia. Cosac \& Naify. (Trabalho original publicado em 1950)

Metri, M. (2014). Poder, riqueza e moeda na Europa medieval: A preeminência naval, mercantil e monetária da sereníssima República de Veneza nos séculos XIII e XV. Editora FGV. 
Morriss, A. (2008). Anarcho-Capitalism. In R. Hamowy (Ed.), The Encyclopedia of Libertarianism (pp. 13-14). Sage.

Nakamoto, S. (2008). Bitcoin: A peer-to-peer electronic cash system. https:// bitcoin.org/bitcoin.pdf

Nicoletti, B. (2017). The future of fintech: Integrating finance and technology in financial services. Palgrave MacMillan.

Nietzsche, F. (1998). Genealogia da moral: Uma polêmica. Companhia das Letras. (Trabalho original publicado em 1887)

Paraná, E. (2020). Bitcoin: A utopia tecnocrática do dinheiro apolítico. Autonomia Literária.

Rothbard, M. N. (2013). Por uma nova liberdade: O manifesto libertário. Instituto von Mises Brasil.

Schumpeter, J. A. (2010). Capitalism, socialism and democracy. Routledge.

Simiand, F. (2018). A moeda, realidade social. Edusp.

Simmel, G. (2004). The philosophy of money (3a ed.). Routledge.

Srnicek, N. (2018). Platform capitalism. Polity.

Steiner, P. (2018). Simiand e a sociologia econômica da moeda. In F. Simiand, A moeda, realidade social (pp. 125-136). Edusp.

Streeck, W. (2018). Tempo comprado: A crise adiada do capitalismo democrático. Boitempo.

Théret, B. (2008). Os três estados da moeda: Abordagem interdisciplinar do fato monetário. Economia e Sociedade, 17(32), 1-28.

Ulrich, F. (2014). Bitcoin: A moeda na era digital. Instituto von Mises Brasil.

Varoufakis, Y. (2016). O minotauro global: A verdadeira origem da crise financeira e o futuro da economia global. Autonomia Literária.

Waizbort, L. (2013). As aventuras de Georg Simmel (3a ed.). Editora 34; Programa de Pós-Graduação em Sociologia/Universidade de São Paulo.

Weber, M. (1999). Economia e sociedade: Fundamentos da sociologia compreensiva. Editora UnB; Imprensa Oficial do Estado de São Paulo. (Trabalho original publicado em 1921)

Weber, M. (2004). A ética protestante e o espírito do capitalismo. Companhia das Letras. (Trabalho original publicado em 1920)

Zelizer, V. A. (1994). The social meaning of money: Pin money, paychecks and other currencies. Basic Books.

Artigo recebido em 13 de julho de 2020 e aprovado em 28 de abril de 2021. 